\title{
CS Research Square \\ The prediction of surgical intervention in patients with tubo-ovarian abscess
}

\section{Jong Ha Hwang ( $\sim$ jh36640@hanmail.com )}

Catholic Kwandong University International Saint Mary's Hospital

\section{Bo Wook Kim}

Catholic Kwandong University International Saint Mary's Hospital

\section{Research article}

Keywords: C-reactive protein, erythrocyte sedimentation rate, surgical intervention, tubo-ovarian abscess, white blood cell

Posted Date: February 14th, 2020

DOI: https://doi.org/10.21203/rs.2.23551/v1

License: () (1) This work is licensed under a Creative Commons Attribution 4.0 International License. Read Full License

Version of Record: A version of this preprint was published at Journal of Obstetrics and Gynaecology on February 25th, 2021. See the published version at https://doi.org/10.1080/01443615.2020.1867965. 


\section{Abstract}

Background: The prediction of antibiotic treatment failure is helpful to identify patients with a high likelihood of needing surgical treatment early in patients diagnosed with tubo-ovarian abscess (TOA). The aim of this study was to compare the clinical characteristics of patients with TOA) who responded to medical treatment and those who underwent surgical intervention due to medical treatment failure. Material and Methods: Electronic medical records were evaluated retrospectively to identify patients who were diagnosed with TOA and hospitalized in our obstetrics and gynecology department between March 2014 and June 2019. Demographic, clinical, and laboratory data including white blood cell (WBC) count, erythrocyte sedimentation rate (ESR), and C-reactive protein (CRP) were compared between the medical treatment group and the surgical intervention group. Logistic regression was used to determine the independent predictors of treatment failure. Results: Patient age, TOA diameter, WBC count, CRP, and ESR were significantly different between the groups. On multiple regression analysis, significant correlations were identified between age $(p=0.001), \operatorname{ESR}(p=0.045)$, and failure of medical treatment. TOA diameter $(p=0.065)$ showed a borderline association with surgical intervention. The risk group was defined as the combination of factors producing a risk score $>2$. The area under the curve (AUC) for the risk group (age $>34.3$ years, ESR $>45 \mathrm{~mm} / \mathrm{h}$, and TOA size $>5.9 \mathrm{~cm}$ ) was 0.844 . The sensitivity, specificity, accuracy, PPV, and NPV were 93.8\%, 75\%, 83.3\%, 75\%, and 93.8\%, respectively. Conclusions: The risk of needing surgical intervention in TOA patients can be predicted using ESR in addition to age and TOA size as risk factors.

\section{Introduction}

Pelvic inflammatory disease (PID) causes inflammation in the uterus, ovaries, fallopian tubes, and adjacent pelvic organs including bowel (1). Tubo-ovarian abscesses (TOAs) may form in cases of severe PID and can lead to sepsis if the abscess ruptures. TOAs are thought to occur when pathogens spread from the cervix to the endometrium and through the fallopian tube into the peritoneal cavity, causing pelvic peritonitis and abscess formation. TOA affects sexually active women of reproductive age and is associated with repeated hospitalization, infertility, ectopic pregnancies, pelvic adhesions, and chronic pelvic pain (1-3).

To diagnosis TOA in patients with suspected PID, imaging methods such as ultrasound, CT, and MRI are used. Gynecologic ultrasound is the most common imaging modality for differentiating between hemorrhagic ovarian cysts, endometriosis, and TOA in patients with clinically suspected TOA. Treatment of TOA includes broad spectrum antibiotics or surgical interventions such as drainage or more invasive procedures. Broad spectrum antibiotics targeting anaerobes and gram-negative aerobes is the first line treatment and is effective in $70 \%$ of TOA patients $(4,5)$. Surgical intervention is needed in approximately $30 \%$ of TOA patients who do not respond to antibiotics or whose abscesses rupture. In patients diagnosed with TOA, prediction of antibiotic treatment failure may help in the early identification of patients with a high likelihood of needing surgical treatment. The aim of this study was to determine the clinical characteristics associated with the need for surgical intervention.

\section{Methods}


This retrospective study was performed at the International Saint Mary's Hospital, Incheon, South Korea. The electronic medical records of patients admitted with suspected tubo-ovarian abscess ( TOA) between March 2014 and June 2019 were reviewed. This study was approved by the Institutional Review Board of Catholic Kwandong University, International Saint Mary's Hospital (IS19RISI0057).

A diagnosis of TOA was made in patients who presented with lower abdominal and pelvic pain, vaginal discharge, and cervical motion tenderness during gynecologic examination. Additional findings included fever; elevated white blood cell (WBC) count, erythrocyte sedimentation rate (ESR), and CRP (C-reactive protein); and a complex adnexal mass on pelvic ultrasonography, computed tomography, or magnetic resonance imaging. Hospitalization and intravenous antibiotics were recommended for all patients diagnosed with TOA. The antibiotic regimen included ceftriaxone $2.0 \mathrm{~g}$ iv every 24 hours or ceftriaxone $1.0 \mathrm{~g}$ iv every 12 hours, metronidazole $500 \mathrm{mg}$ iv every 8 hours, and isepamicin $400 \mathrm{mg}$ iv every 24 hours.

Surgical intervention was considered if the patient's symptoms did not improve after 72 hours of antibiotic administration. Specifically, the criteria for considering surgical treatment were: persistent fever, enlarging TOA, worsening pelvic tenderness, and acute clinical deterioration such as any sign of sepsis, ruptured abscess, or generalized peritonitis. Surgical treatment was also considered to rule out malignancy when the patient was elderly and the tumor marker levels remained high even though symptoms improved after antibiotic treatment.

Conservative treatment was provided with follow-up imaging if the clinical signs improved and tumor marker levels decreased. Postoperative antibiotics were continued until clinical improvement was achieved.

Demographic, clinical, and laboratory data were compared between patients who were managed conservatively and patients who underwent surgical treatment. Demographic data included age, parity, body mass index (BMI), marital status, menopause status, smoking, alcohol, number and type of previous pelvic surgery procedures, and medical history of intrauterine device (IUD) insertion or previous PID. Clinical and laboratory data included vital signs, length of hospital stay, mass location, imaging modality for diagnosis, the largest diameter of the TOA mass, and results of blood panels including a serum tumor marker (CA 125) and inflammatory markers such as ESR and CRP. The TOA size was defined as the largest diameter measured by transvaginal ultrasonography.

Peak fever was defined as the highest body temperature during treatment in the conservative group and the highest preoperative body temperature in the surgical intervention group. The highest WBC counts $\left(\mathbb{\Delta} 10^{3} / \mathrm{mL}\right)$, ESR, CRP, and neutrophil and lymphocyte percentages were selected during hospitalization in the conservative treatment group and the highest values before operation were selected in the surgical intervention group. Absolute neutrophil count (ANC) and neutrophil-to-lymphocyte ratio (NLR) were calculated from the complete blood cell count (CBC) and recorded. In the surgical intervention group, type and technique of surgery and pathology results were described.

The data were entered into Microsoft Excel and analyzed using SPSS statistical software, version 20 (SPSS Inc, Chicago, IL, USA). Median and interquartile range were used for descriptive statistics. The characteristics of the two groups were compared using Student's t-test and the $\chi^{2}$ test. Fisher's exact test was used for categorical variables with small samples. A binary logistic regression was performed for significant variables in the univariate and multivariate analysis to assess the correlation between clinical findings and the risk of surgical 
intervention in patients with TOA. All statistical tests were 2-sided, and a p value of $<0.05$ was considered significant. A receiver operating characteristic (ROC) curve was used to determine the cutoff of clinical characteristics with regard to the need for surgical intervention. The 95\% confidence interval $(\mathrm{Cl})$ of the area under the curve (AUC) was determined. We chose optimum diagnostic thresholds by using coordinates from the ROC curve. The sensitivity, specificity, accuracy, positive predictive value (PPV), negative predictive value (NPV), and odds ratio of significant variables were calculated to predict the risk of surgical intervention in patients with TOA. We also combined significant variables in the multivariate analysis to maximize the predictability of surgical intervention.

\section{Results}

During the study period, 244 patients were diagnosed with PID. Of these, 72 patients received a final diagnosis of TOA; 40 were treated with intravenous antibiotics (conservative treatment group), and 32 did not respond to medical treatment and needed further surgery or abscess drainage (surgical interventional group). Table 1 shows the patient demographic data for the two groups. The overall median age was 31.1 years (interquartile range: $25.2-42.5$ years) in the conservative treatment group and 47 years (interquartile range: $41.8-50$ years) in the surgical intervention group; the difference was significant $(p<0.001)$. There were no significant betweengroup differences in BMI, number and type of previous abdominal surgeries, IUD use, history of previous PID, alcohol, or smoking. The numbers of patients who were nulliparous $(p<0.001)$, single $(p<0.001)$, and premenopausal $(p=0.003)$ were significantly higher in the conservative treatment group.

Table 2 shows clinical and laboratory data from the records of the two groups of patients with TOA. There were no significant differences in peak fever, fever higher than $38^{\circ} \mathrm{C}$, mass location, imaging modality, and tumor maker (CA 125) level. The median (interquartile range) WBC count, ESR, CRP, mass size, and length of hospital stay were higher in the surgical intervention group than in the conservative treatment group: 9,775.0 $\mu$ l (7842.5-12547.5) vs 12,600 $\mu \mathrm{l}$ (10460-15.57), $\mathrm{p}=0.006 ; 34 \mathrm{~mm} / \mathrm{h}(22.5-60.3)$ vs $56.5 \mathrm{~mm} / \mathrm{h}(49.7-86.0), \mathrm{p}<$ $0.001 ; 42.7 \mathrm{mg} / \mathrm{l}(13.2-106.4)$ vs $119.0 \mathrm{mg} / \mathrm{l}(69.8-190), \mathrm{p}=0.001 ; 5.1 \mathrm{~cm}(4.4-5.7)$ vs $6.9 \mathrm{~cm}(6.0-7.6), \mathrm{p}<$ 0.001 ; and 6.0 days $(5.0-9.0)$ vs 7.0 days $(4.8-10.4), p=0.017$, respectively.

Table 3 shows the surgery and pathology outcomes in the 32 patients comprising the surgical intervention group. Laparoscopy and laparotomy were performed in 17 (53.1\%) and 14 (43.8\%) patients, respectively. One patient was treated with abscess drainage via culdotomy and pigtail insertion, 15 patients underwent unilateral salpingectomy or unilateral salpingo-oophorectomy, and 12 patients underwent bilateral salpingectomy or bilateral salpingo-oophorectomy. Four cases of total hysterectomy in addition to adnexal surgery were identified. Four patients underwent appendectomy because the TOA spread to the periappendiceal area. One patient underwent low anterior resection because the TOA resulted from colon cancer with perforation. Fistulectomy was performed in one patient with a fistula between the TOA and abdominal skin. Two patients were diagnosed with actinomycosis.

Univariate analysis was performed by binary logistic regression. Multivariate analysis was performed and cutoff values based on the ROC curve were determined using variables found to be significant in the univariate analysis. As shown in Table 4, five variables remained significantly associated with the risk of surgical intervention: age (OR, 1.134; 95\% confidence interval [Cl], 1.065-1.209); mass size (OR, 1.947; 95\% Cl, 1.313- 
2.887); ESR (OR, 1.037; 95\% Cl, 1.016-1.059); CRP (OR, 1.012; 95\% Cl, 1.004-1.019); and WBC (OR, 1.000; 95\% $\mathrm{Cl}, 1.000-1.000)$. Only age $(p=0.001)$ and ESR $(p=0.045)$ remained significant variables in the multivariate analysis. Mass size showed borderline significance $(p=0.065)$.

Table 5 shows cutoff values and AUC based on the ROC curve for variables found to be significant in the univariate analysis. Sensitivity, specificity, accuracy, PPV, and NPV were calculated using the cutoff values. As a single variable, age (cutoff value $>34.3$ years and AUC 0.822) showed the highest sensitivity (93.8\%) and NPV (87.5\%) for predicting surgical intervention in TOA patients. However, the specificity of age was only $35 \%$. The accuracy of mass size (cutoff value $>5.9 \mathrm{~cm}$, AUC 0.780) was the highest and ESR (cutoff value $45 \mathrm{~mm} / \mathrm{h}$ and AUC 0.750) showed the highest PPVs (Fig. 1).

To increase the predictability, age and ESR, which were significant variables in the multivariate analysis, were combined. The combination index of age $>34.2$ years and ESR $>45 \mathrm{~mm} / \mathrm{h}$ had an accuracy of $81.9 \%$, which was higher than that of the single variables. Risk scoring was performed based on age, ESR, and mass size. Each variable with a value higher than the cutoff value received a scored of 1 , and the combination of variables resulting in a total score of more than 2 points was categorized as the risk group. The AUCs of the risk group and combination index were 0.844 (sensitivity $93.8 \%$, specificity $75.0 \%$, accuracy $83.3 \%$, PPV $75 \%$, and NPV $93.8 \%$ ) and 0.819 (sensitivity $81.3 \%$, specificity $82.5 \%$, accuracy $81.9 \%$, PPV $78.8 \%$, and NPV $84.6 \%$ ), respectively (Fig. 2).

\section{Discussion}

Early surgical intervention can reduce morbidity and mortality in TOA patients who do not respond to antibiotics. Several studies of demographic and clinical characteristics associated with antibiotic treatment failure in TOA patients have shown that the TOA size and age of the patient are significantly related and proportional to the need for surgical treatment (6-11). Early recognition of a patient's risk of antibiotic treatment failure alerts clinicians to the need to change the treatment strategy, thereby reducing acute and longterm complications of TOA. In accordance with the results of previous studies, older patients (over 34 years) with large TOAs (more than $5.9 \mathrm{~cm}$ ) were less likely to respond to antibiotics and more likely to undergo invasive treatment. Age was the strongest predictor of failed antibiotic treatment in this study.

TOA was associated with increased ESR, CRP, and WBC. Previous studies reported that these biological markers help to predict response in TOA patients treated with antibiotics. High WBC counts or high CRP have been reported to lead to antibiotics failure (7). However, the results are inconsistent. Akkurt et al. found no difference in CRP levels between TOA patients who responded to antibiotics and those who did not (12). Yildirim et al. reported that WBCs and neutrophils were elevated in TOA patients, and neutrophils were elevated even when the WBC count was normal (13); they also found that lymphocytes were relatively decreased, resulting in an increase in the neutrophil-to-lymphocyte ratio (NLR). Alay et al. reported that neutrophil counts were significantly higher in TOA patients with no response to medication and that the NLR could be used to predict non-response to medication in TOA patients (10).

Most of these studies were evaluated based on the patient's clinical characteristics on the day of admission $(10,11)$. However, some patients who did not have a fever on the day of hospitalization may have had a fever later. CRP and ESR levels can also increase after hospitalization and starting antibiotics. WBC and neutrophil 
counts also may increase on the second or third day of hospitalization. Therefore, we analyzed the highest values recorded during hospitalization. Because the level of inflammation increases due to surgery, we used the highest values obtained before surgery in the surgical intervention group. In our study, ESR, CRP, and WBC count were statistically significant in the univariate analysis, but only ESR was significant in the multivariate analysis. Neutrophil counts and the NLR had only borderline significance in the univariate analysis.

Simultaneous consideration of multiple variables can improve predictability. Fouks et al. scored risk by weighting age at hospitalization ( $>35$ years), abscess size $(\geq 70 \mathrm{~mm}), \mathrm{WBC}$ count $\left(>16,000 / \mathrm{mm}^{3}\right)$, and bilaterality (11). They excluded the CRP value because it was not significant in the univariate analysis. Four groups were defined based on the risk score, and the risk of antibiotic treatment failure was positively correlated with a higher risk score. In the highest risk group, there was a $92 \%$ chance of invasive treatment such as surgery or drainage. We reconfirmed that age (>34.3 years) and the size of the abscess $(>59 \mathrm{~mm})$ are risk factors, and the cutoff values are also similar. The risk group sensitivity in our study was $93.8 \%$.

We observed higher mean values for WBCs, CRP, and ESR (all inflammatory markers) in the surgical intervention group than in the conservative group. The frequency of fever above $38^{\circ} \mathrm{C}$ and peak fever during admission were not statistically different between the groups, which accords with the results of previous studies (11) (14). To our knowledge, this is the first report of the value of inflammatory markers obtained during hospitalization for predicting antibiotic treatment failure in patients with TOA. Previous studies were based on inflammatory markers obtained on the day of admission (10) (11) and mainly referred to WBC and CRP as useful inflammatory markers for predicting conservative treatment failure. In this study, the WBC, CRP, and ESR levels were all higher in the surgical intervention group than in the conservative treatment group. However, only ESR was a significant predictor in the multivariate analysis. This difference may be due to the fact that, unlike previous studies, our study used the highest inflammatory marker levels recorded during the entire hospital stay in the conservative treatment group and during hospitalization before surgery in the surgical intervention group.

ESR and CRP are widely used inflammatory markers. Because of their lack of sensitivity and specificity, ESR and CRP should be interpreted in the context of clinical history and physical exam for the diagnosis of TOA. Discrepancies between ESR and CRP measurements are common, especially in chronic inflammatory diseases (15). TOA is a late complication of PID. CRP is preferred as a serologic marker for acute inflammatory conditions (16). CRP levels tend to increase rapidly after the onset of inflammation and drop quickly with the administration of antibiotics (17). The ESR changes more slowly than the CRP level during antibiotic therapy (17) (18), which may explain why ESR was more useful for predicting surgical intervention than CRP in this study.

In conclusion, the addition of ESR to the previously identified risk factors of age and TOA size predicts the likelihood of surgical intervention. The limitations of this study relate to its retrospective design and small study population derived from a single institution. Future prospective controlled studies are required to verify our findings.

\section{Declarations}

Conflict of interest statement 
The authors declare that there are no conflicts of interest relevant to this study.

\section{References}

1. Granberg S, Gjelland K, Ekerhovd E. The management of pelvic abscess. Best Pract Res Clin Obstet Gynaecol. 2009;23(5):667-78.

2. Bugg CW, Taira T. Pelvic Inflammatory Disease: Diagnosis And Treatment In The Emergency Department. Emerg Med Pract. 2016;18(12):1-24.

3. Gradison M. Pelvic inflammatory disease. Am Fam Physician. 2012;85(8):791-6.

4. Wiesenfeld HC, Sweet RL. Progress in the management of tuboovarian abscesses. Clin Obstet Gynecol. 1993;36(2):433-44.

5. McNeeley SG, Hendrix SL, Mazzoni MM, Kmak DC, Ransom SB. Medically sound, cost-effective treatment for pelvic inflammatory disease and tuboovarian abscess. Am J Obstet Gynecol. 1998;178(6):1272-8.

6. Kinay T, Unlubilgin E, Cirik DA, Kayikcioglu F, Akgul MA, Dolen I. The value of ultrasonographic tubo-ovarian abscess morphology in predicting whether patients will require surgical treatment. Int J Gynaecol Obstet. 2016;135(1):77-81.

7. Dewitt J, Reining A, Allsworth JE, Peipert JF. Tuboovarian abscesses: is size associated with duration of hospitalization \& complications? Obstet Gynecol Int. 2010;2010:847041.

8. Halperin R, Levinson O, Yaron M, Bukovsky I, Schneider D. Tubo-ovarian abscess in older women: is the woman's age a risk factor for failed response to conservative treatment? Gynecol Obstet Invest. 2003;55(4):211-5.

9. Habboub AY. Middlemore Hospital experience with tubo-ovarian abscesses: an observational retrospective study. Int J Womens Health. 2016;8:325-40.

10. Alay I, Kaya C, Karaca I, Eren E, Hosgoren M, Aslanova F, et al. The effectiveness of neutrophil to lymphocyte ratio in prediction of medical treatment failure for tubo-ovarian abscess. J Obstet Gynaecol Res. 2019;45(6):1183-9.

11. Fouks Y, Cohen A, Shapira U, Solomon N, Almog B, Levin I. Surgical Intervention in Patients with TuboOvarian Abscess: Clinical Predictors and a Simple Risk Score. J Minim Invasive Gynecol. 2019;26(3):53543.

12. Akkurt MO, Yalcin SE, Akkurt I, Tatar B, Yavuz A, Yalcin Y, et al. The evaluation of risk factors for failed response to conservative treatment in tubo-ovarian abscesses. J Turk Ger Gynecol Assoc. 2015;16(4):22630.

13. Yildirim M, Turkyilmaz E, Avsar AF. Preoperative Neutrophil-to-Lymphocyte Ratio Has a Better Predictive Capacity in Diagnosing Tubo-Ovarian Abscess. Gynecol Obstet Invest. 2015;80(4):234-9.

14. Lee SW, Rhim CC, Kim JH, Lee SJ, Yoo SH, Kim SY, et al. Predictive Markers of Tubo-Ovarian Abscess in Pelvic Inflammatory Disease. Gynecol Obstet Invest. 2015.

15. Bray C, Bell LN, Liang H, Haykal R, Kaiksow F, Mazza JJ, et al. Erythrocyte Sedimentation Rate and Creactive Protein Measurements and Their Relevance in Clinical Medicine. WMJ. 2016;115(6):317-21.

16. Keenan RT, Swearingen CJ, Yazici Y. Erythrocyte sedimentation rate and C-reactive protein levels are poorly correlated with clinical measures of disease activity in rheumatoid arthritis, systemic lupus erythematosus and osteoarthritis patients. Clin Exp Rheumatol. 2008;26(5):814-9. 
17. Shusterman N, Kimmel PL, Kiechle FL, Williams S, Morrison G, Singer I. Factors influencing erythrocyte sedimentation in patients with chronic renal failure. Arch Intern Med. 1985;145(10):1796-9.

18. Litao MK, Kamat D. Erythrocyte sedimentation rate and C-reactive protein: how best to use them in clinical practice. Pediatr Ann. 2014;43(10):417-20.

\section{Tables}


Table 1. Demographic data of patients with TOA

\begin{tabular}{|c|c|c|c|}
\hline & $\begin{array}{l}\text { Conservative treatment group } \\
(\mathrm{N}=40)\end{array}$ & $\begin{array}{l}\text { Surgical intervention group } \\
(\mathrm{N}=32)\end{array}$ & $\begin{array}{l}P \\
\text { value }\end{array}$ \\
\hline Age (year) & $31.1(25.2-42.5)$ & $47(41.8-50)$ & $\begin{array}{l}< \\
0.001\end{array}$ \\
\hline \multicolumn{4}{|l|}{ Parity } \\
\hline None & $23(57.5)$ & $3(9.4)$ & $\begin{array}{l}< \\
0.001\end{array}$ \\
\hline One & $3(7.5)$ & $7(21.9)$ & 0.097 \\
\hline Two & $12(30)$ & $15(46.9)$ & 0.142 \\
\hline More than three & $2(5)$ & $7(21.9)$ & 0.068 \\
\hline BMI $\left(\mathrm{kg} / \mathrm{m}^{2}\right)$ & $22.4(20.5$ - 24.8) & $23.2(20.7-26)$ & 0.303 \\
\hline Use of IUD & $2(5)$ & $5(15.6)$ & 0.230 \\
\hline History of PID & $3(7.5)$ & $5(15.6)$ & 0.453 \\
\hline Alcohol & $12(30)$ & $8((25)$ & 0.638 \\
\hline Smoking & $9(22.5)$ & $5(15.6)$ & 0.464 \\
\hline \multicolumn{4}{|l|}{$\begin{array}{l}\text { Previous pelvic surgery, } \\
\text { Number }\end{array}$} \\
\hline None & $28(70)$ & $17(53.1)$ & 0.142 \\
\hline One time & $7(17.5)$ & $6(18.8)$ & 0.891 \\
\hline Two times & $4(10)$ & $6(18.8)$ & 0.323 \\
\hline More than three times & $1(2.5)$ & $3(9.4)$ & 0.317 \\
\hline \multicolumn{4}{|l|}{$\begin{array}{l}\text { Previous pelvic surgery, } \\
\text { type }\end{array}$} \\
\hline Cesarean section & $5(12.5)$ & $10(31.3)$ & 0.052 \\
\hline Appendectomy & $6(15)$ & $1(3.1)$ & 0,123 \\
\hline Hysterectomy & $2(5)$ & $1(3.1)$ & 1.000 \\
\hline Myomectomy & $1(2.5)$ & $1(3.1)$ & 1.000 \\
\hline Others & $1(2.5)$ & $4((12.5)$ & 1.064 \\
\hline \multicolumn{4}{|l|}{ Marital status } \\
\hline Single & $16(40)$ & $1(3.1)$ & $\begin{array}{l}< \\
0.001\end{array}$ \\
\hline Married & $24(60)$ & $31(96.9)$ & $\begin{array}{l}< \\
0.001\end{array}$ \\
\hline
\end{tabular}


Menopause status

Premenopause

38 (70)

22 (68.8)

0.003

Postmenopause

2 (5)

10 (31.3)

0.004

All continuous variables are expressed as median (interquartile range). All categorical variable are expressed as number (\%) 
Table 2. Clinical and laboratory data in patients with TOA

\begin{tabular}{|c|c|c|c|}
\hline & $\begin{array}{l}\text { Conservative treatment } \\
\text { group }(\mathrm{N}=40)\end{array}$ & $\begin{array}{l}\text { Surgical intervention group } \\
(\mathrm{N}=32)\end{array}$ & $P$ value \\
\hline Peak fever & $37.3(37$ - 37.9) & $37.7(37.5-38.1)$ & 0.082 \\
\hline $\begin{array}{l}\text { Fever }>38 \\
{ }^{\circ} \mathrm{C} \text { (Number) }\end{array}$ & 9 & 13 & 0.097 \\
\hline WBC count (ul) & $9,775.0(7842.5-12547.5)$ & $12,600(10460-15057)$ & 0.006 \\
\hline $\operatorname{ESR}(\mathrm{mm} / \mathrm{h})$ & $34(22.5-60.3)$ & $56.5(49.7-86.0)$ & $<0.001$ \\
\hline CRP (mg/l) & $42.7(13.2-106.4)$ & $119.0(69.8-190)$ & 0.001 \\
\hline CA 125 (Unit/ml) & $38.6(19-291.2)$ & $36.5(17.1-75.5)$ & 0.135 \\
\hline ANC & 7,929.6 (5235.1- 10253.7) & $9,799.4(8107.7-12894.2)$ & 0.006 \\
\hline Neutrophil (\%) & $77.3(68.5-83.3)$ & $80.0(76.8-85.2)$ & 0.063 \\
\hline Lymphocyte (\%) & $15.9(10.0-22.2)$ & $12.5(8.0-16.4)$ & 0.050 \\
\hline $\mathrm{N} / \mathrm{L}$ ratio & $4.9(6.2-22.5)$ & $8.8 \pm 6.1$ & 0.062 \\
\hline Mass size (cm) & $5.1(4.4-5.7)$ & $6.9(6.0-7.6)$ & $<0.001$ \\
\hline $\begin{array}{l}\text { length of hospital stay } \\
\text { (days) }\end{array}$ & $6.0(5.0-9.0)$ & $7.0(4.8-10.4)$ & 0.017 \\
\hline \multicolumn{4}{|l|}{$\begin{array}{l}\text { Mass location } \\
\text { (Number) }\end{array}$} \\
\hline Right & $14(35)$ & $9(28.1)$ & 0.534 \\
\hline Left & $10(25)$ & $15(46.9)$ & 0.053 \\
\hline Both & $16(40)$ & $8(25)$ & 0.180 \\
\hline \multicolumn{4}{|l|}{$\begin{array}{l}\text { Imaging modality } \\
\text { (Number) }\end{array}$} \\
\hline US only & $14(35)$ & $7(21.9)$ & 0.223 \\
\hline $\mathrm{US}+\mathrm{CT}$ & $26(65)$ & $22(68.8)$ & 0.737 \\
\hline US + MRI & 0 & $2(6.3)$ & 0.194 \\
\hline $\mathrm{US}+\mathrm{CT}+\mathrm{MRI}$ & 0 & $1(3.1)$ & 0.444 \\
\hline
\end{tabular}

All continous variables are expressed as median (interquartile range). All categorical variables are expressed as number (\%)

WBC; white blood cell, ESR; estimated sedimentation rate, CRP; C-reactive protein, ANC; absolute neutrophil count, N/L ratio; neutrophil/lymphocyte, ratio,

US; pelvic ultrasonography, CT; computer tomography, MRl; magnectic resonance image 


\begin{tabular}{|l|l|}
\hline \multicolumn{2}{|l|}{ Table 3. Characteristics of surgery and pathology in surgical intervention group (N=32). } \\
\hline Operation & Surgical intervention group \\
\hline Laparoscopy & $17(53.1)$ \\
\hline Laparotomy & $14(43.8)$ \\
\hline Abscess drainage ${ }^{\text {a }}$ & $1(3.1)$ \\
\hline Type of surgery & \\
\hline Unilateral salpingectomy & $8(25)$ \\
\hline Bilateral salpingectomy & $6(18.8)$ \\
\hline Unilateral salpingo-oophorectomy & $7(21.9)$ \\
\hline Bilateral salpingo-oophorectomy & $6(18.8)$ \\
\hline Total hysterectomy + adnexal surgery & $4(12.5)$ \\
\hline Co-operation & \\
\hline Appendectomy & $4(12.5)$ \\
\hline Colon surgery & $2(6.3)$ \\
\hline Fistulectomy & $1(3.1)$ \\
\hline Omental resection & $1(3.1)$ \\
\hline Myomectomy & $1(3.1)$ \\
\hline Anterior abdominal wall resection & $1(3.1)$ \\
\hline Cholecystectomy & $1(3.1)$ \\
\hline Pathology & $29(90.6)$ \\
\hline Abscess & $2(6.3)$ \\
\hline Colinomycosis & \\
\hline b : Fistula between tubo-ovarian abscess and skin cancer & \\
\hline
\end{tabular}

All variables are expressed as number (\%). 
Table 4. Univariate and multivariate logistic regression analysis for surgical management in patient with TOA

\begin{tabular}{|c|c|c|c|c|c|c|}
\hline \multirow[t]{2}{*}{ Variables } & \multicolumn{3}{|c|}{ Univariate analysis } & \multicolumn{3}{|c|}{ Multivariate analysis } \\
\hline & OR & $95 \% \mathrm{Cl}$ & $P$ value & OR & $95 \% \mathrm{Cl}$ & $P$ value \\
\hline Age (year) & 1.135 & $1.065-1.209$ & 0.000 & 1.134 & $1.051-1.224$ & 0.001 \\
\hline Mass size (cm) & 1.947 & $1.313-2.887$ & 0.001 & 1.547 & $0.973-2.459$ & 0.065 \\
\hline $\mathrm{ESR}(\mathrm{mm} / \mathrm{h})$ & 1.037 & $1.016-1.059$ & 0.001 & 1.041 & $1.001-1.083$ & 0.045 \\
\hline CRP (mg/dl) & 1.012 & $1.004-1.019$ & 0.002 & 0.994 & $0.982-1.007$ & 0.351 \\
\hline WBC (cell/mm3) & 1.000 & $1.000-1.000$ & 0.013 & 1.000 & $1.000-1.000$ & 0.728 \\
\hline Neutrophil (\%) & 1.050 & $0.996-1.106$ & 0.068 & & & \\
\hline $\mathrm{N} / \mathrm{L}$ ratio & 1.097 & $0.990-1.215$ & 0.077 & & & \\
\hline
\end{tabular}

WBC; white blood cell, ESR; estimated sedimentation rate, CRP; C-reactive protein, N/L ratio; neutrophil/lymphocyte, ratio

Table 5. AUC values and cuff off points for surgical intervenstion.

\begin{tabular}{|c|c|c|c|c|c|c|c|c|c|}
\hline & $\begin{array}{l}\text { Cut } \\
\text { value }\end{array}$ & AUC & $\begin{array}{l}\mathrm{P} \\
\text { value }\end{array}$ & Sensitivity & Specificity & Accuracy & PPV & NPV & $\begin{array}{l}\text { Odd } \\
\text { ratio }\end{array}$ \\
\hline Age (year) & 34.3 & 0.822 & $\begin{array}{l}< \\
0.001\end{array}$ & $93.8 \%$ & $35.0 \%$ & $61.1 \%$ & $65.2 \%$ & $87.5 \%$ & 13.1 \\
\hline $\begin{array}{l}\text { Mass size } \\
(\mathrm{cm})\end{array}$ & 5.9 & 0.780 & $\begin{array}{l}<.001 \\
0.001\end{array}$ & $78.1 \%$ & $77.5 \%$ & $77.8 \%$ & $73.5 \%$ & $81.6 \%$ & 12.3 \\
\hline $\begin{array}{l}\text { WBC } \\
\text { (cell/mm3) }\end{array}$ & 10450 & 0.697 & 0.004 & $75.0 \%$ & $62.5 \%$ & $68.1 \%$ & $61.5 \%$ & $75.8 \%$ & 5.0 \\
\hline $\begin{array}{l}\text { ESR } \\
(\mathrm{mm} / \mathrm{h})\end{array}$ & 45 & 0.750 & $\dot{0} 001$ & $84.4 \%$ & $70.0 \%$ & $76.4 \%$ & $84.4 \%$ & $84.8 \%$ & 30.2 \\
\hline $\begin{array}{l}\mathrm{CRP} \\
(\mathrm{mg} / \mathrm{dl})\end{array}$ & 138 & 0.716 & 0.002 & $46.9 \%$ & $87.5 \%$ & $69.4 \%$ & $75.0 \%$ & $70.0 \%$ & 7.0 \\
\hline Age and ESR & & 0.819 & $\begin{array}{l}< \\
0.001\end{array}$ & $81.3 \%$ & $82.5 \%$ & $81.9 \%$ & $78.8 \%$ & $84.6 \%$ & 20.4 \\
\hline Risk group & & 0.844 & $<0.001$ & $93.8 \%$ & $75.0 \%$ & $83.3 \%$ & $75.0 \%$ & $93.8 \%$ & 45.0 \\
\hline
\end{tabular}

Risk group : More than two factors as follows age $>34.3, E S R>45$, mass size $>5.9$

AUC; area under curve, PPV; positive predictability value, NPV, negative predictability value 
Figures

\section{ROC curve}

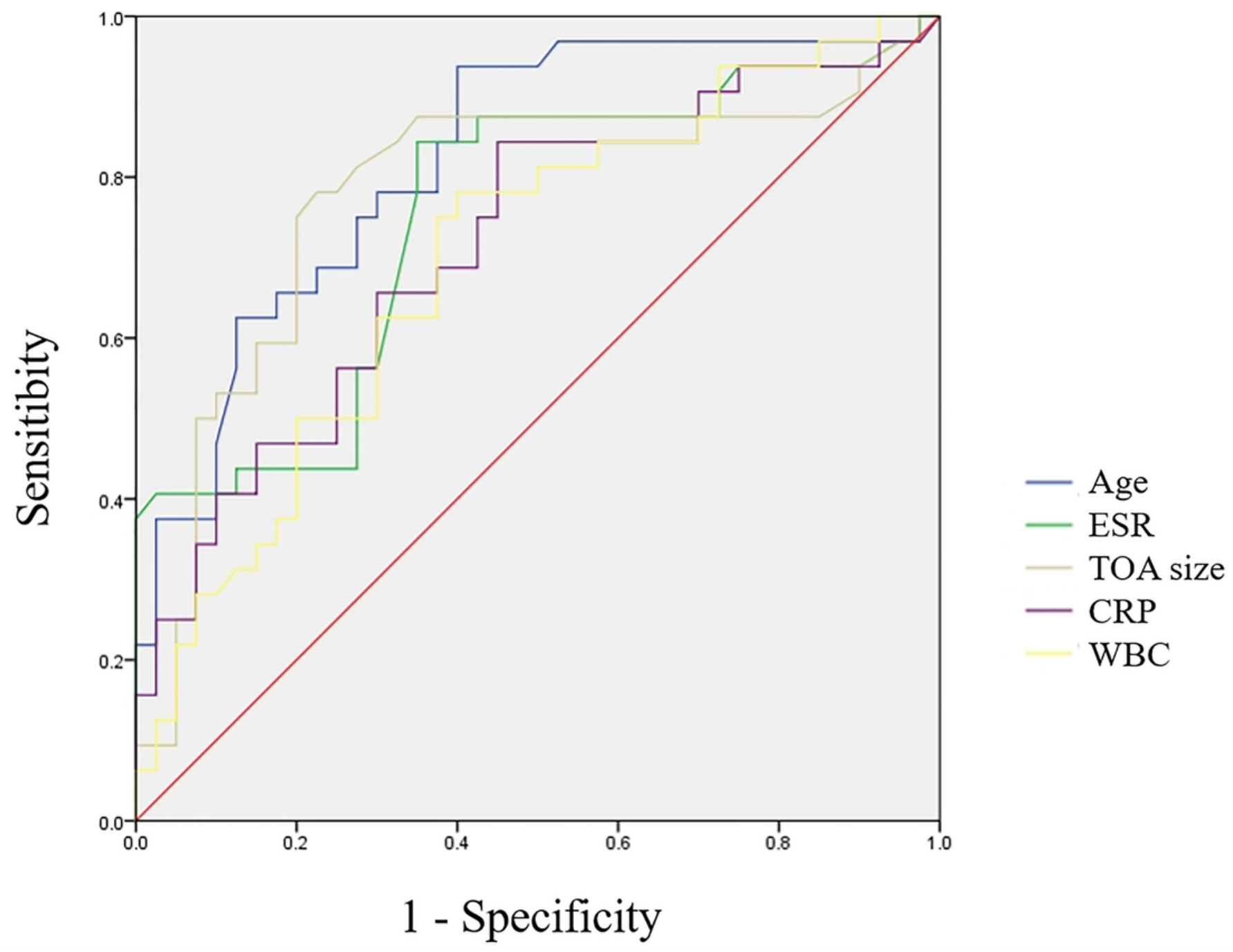

Figure 1

ROC curve for age, ESR, TOA size, CRP, and WBC count (red line: reference) 


\section{ROC curve}

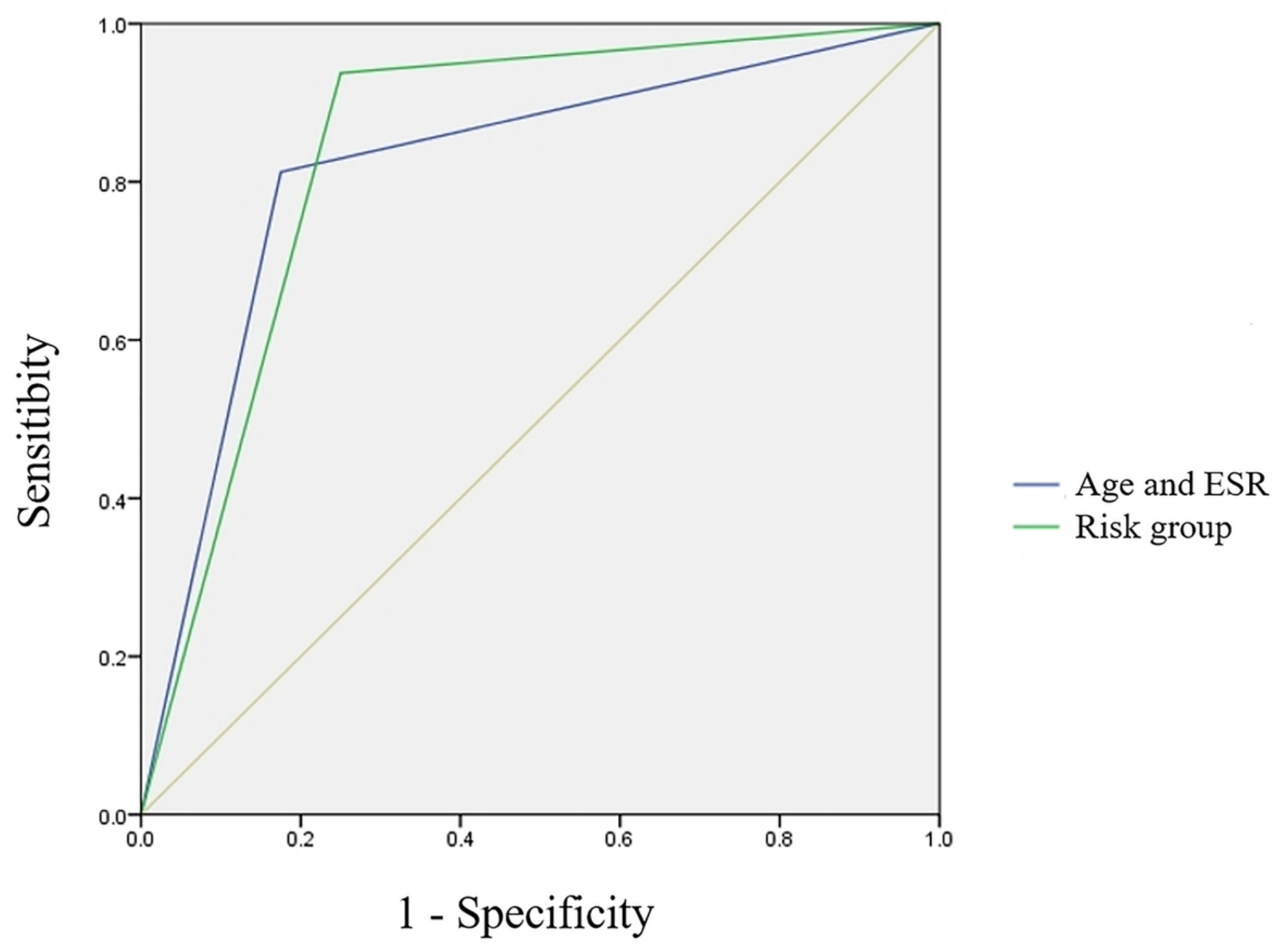

\section{Figure 2}

ROC curve. Blue line: age $>34.3$ years or ESR $>45 \mathrm{~mm} / \mathrm{h}$; green line: the risk group defined by two or more factors (> 34.3 years, ESR $>45 \mathrm{~mm} / \mathrm{h}$, and mass size $>5.9 \mathrm{~cm}$ ); yellow line: reference. 